\title{
+ Konrad Otto Anderegg \\ Secrétaire de la délégation du Comité international de la Croix-Rouge à Batavia ${ }^{2}$
}

Le Comité international a appris avec tristesse la mort de M. Konrad Otto Anderegg, secrétaire de sa délégation à Batavia.

Konrad Otto Anderegg, né le 3I mai r898 à Nesslau dans le Toggenburg, quitta la Suisse très tôt, dès qu'il eut terminé ses études commerciales. Il partit pour Sumatra, où il travailla en qualité d'assistant puis de directeur dans des plantations de caoutchouc et de thé. Ouvert comme il l'était à tous les intérêts, M. Anderegg s'adonna à l'étude de l'ethnographie et de l'histoire des civilisations; il séjourna deux ans à Bali pour y étudier la civilisation et les mœurs des indigènes, puis, peu avant le début de la guerre, il s'établit à Java comme directeur de plantations d'une compagnie anglaise.

C'est en janvier I946 que M. Helbling, délégué du Comité international de la Croix-Rouge dans les Indes orientales, l'appela pour remplir le poste de secrétaire de la délégation à Batavia, où ses expériences, sa connaissance du pays et des habitants, de la langue et des mœurs indonésiennes, furent d'une grande utilité. Plus tard, le Comité international envisagea de nommer $\mathbf{M}$. Anderegg délégué-adjoint, mais la fin prématurée de ce dernier l'empêcha de réaliser son projet.

$\mathrm{Au}$ mois d'avril, M. Anderegg entreprit pour le compte de la "SEAC Red Cross " ${ }^{2}$ un voyage à Bali, et un mois après, le I6 mai, le Comité international apprenait qu'il avait été tué par des indigènes.

Le Comité international est reconnaissant à ce collaborateur, qui servait l'idéal de la Croix-Rouge avec une rare distinction, de l'aide précieuse qu'il lui a apportée en des circonstances très difficiles; il s'associe sincèrement au chagrin de sa famille, à laquelle il exprime sa vive sympathie.

Sitôt que fut connue la mort tragique de M. Anderegg, le Comité international reçut de nombreux témoignages de sympathie et de regrets, auxquels il a été très sensible.

1 Hors-texte

2 Comité de coordination des Croix-Rouges australienne, britannique et de l'Inde, dans le sud-est de l'Asie. 


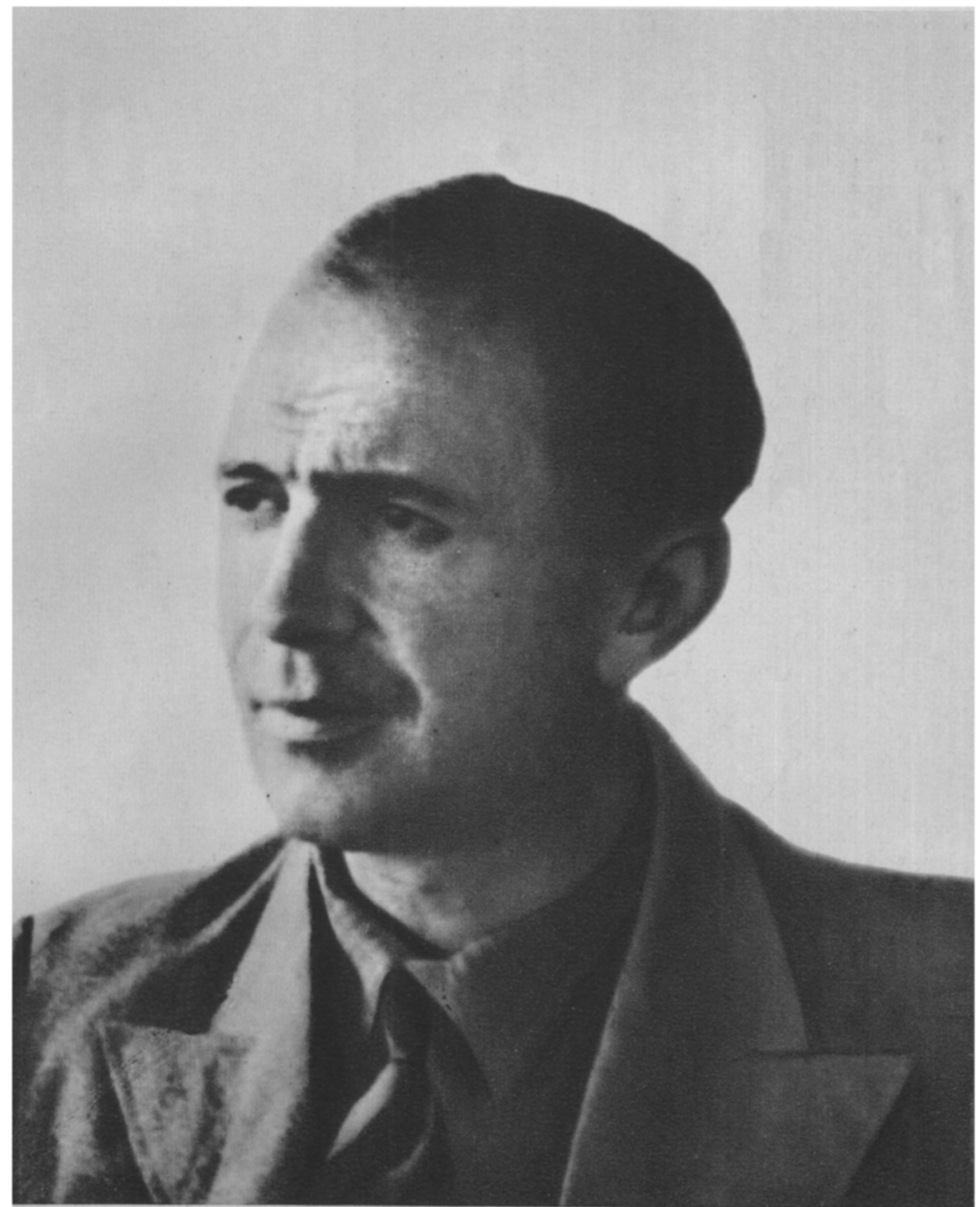

Konrad Otto ANDEREGG

(1898-1946)

Secrétaire de la délégation dı Comité international à Batavia. 